\title{
CAN MOOCS CONTRIBUTE TOWARDS ENHANCING DISRUPTIVE PEDAGOGIC ENCOUNTERS IN HIGHER EDUCATION?
}

\author{
Y. Waghid* \\ Education Policy Studies \\ e-mail: yw@sun.ac.za

\section{F. Waghid*} \\ Centre for Learning Technologies \\ e-mail: Faiq@sun.ac.za \\ *Stellenbosch University \\ Stellenbosch, South Africa
}

\section{ABSTRACT}

In this article, we argue that MOOCs (massive open online courses) have the potential to enhance disruptive pedagogic encounters in higher education, especially in relation to a philosophy of African education. In the first part of the article, we expound on MOOCs as an initiative in higher education that grew out of a concern to advance access to higher education. Paradoxically, we show that MOOCs might not strictly advance equal access and inclusion but have the potential to cultivate student capacities of a critically transformative kind, more specifically, rhizomatic thinking, criticism and recognition of others. In the second part of the article, we show, in reference to an emerging MOOC, how an African philosophy of education should be considered as apposite to advance disruptive pedagogic encounters in higher education.

Keywords: MOOCs, higher education, disruption, pedagogic encounters, rhizomatic thinking, criticism; recognition

\section{INTRODUCTION: MOOCS OPENING UP NEW SPACES FOR ONLINE TEACHING AND LEARNING}

It is widely acknowledged by pioneering MOOCs educators in the world that this fast-growing trend 'will change the [higher] education landscape' (Kim 2015, vii). It is further contended that MOOCs, as a manifestation of the use of technology in higher education, will 'open up new educational possibilities' (Kim 2015, vii). We concur and contend that in South African higher education, MOOCs have emerged as innovative online curriculum and 


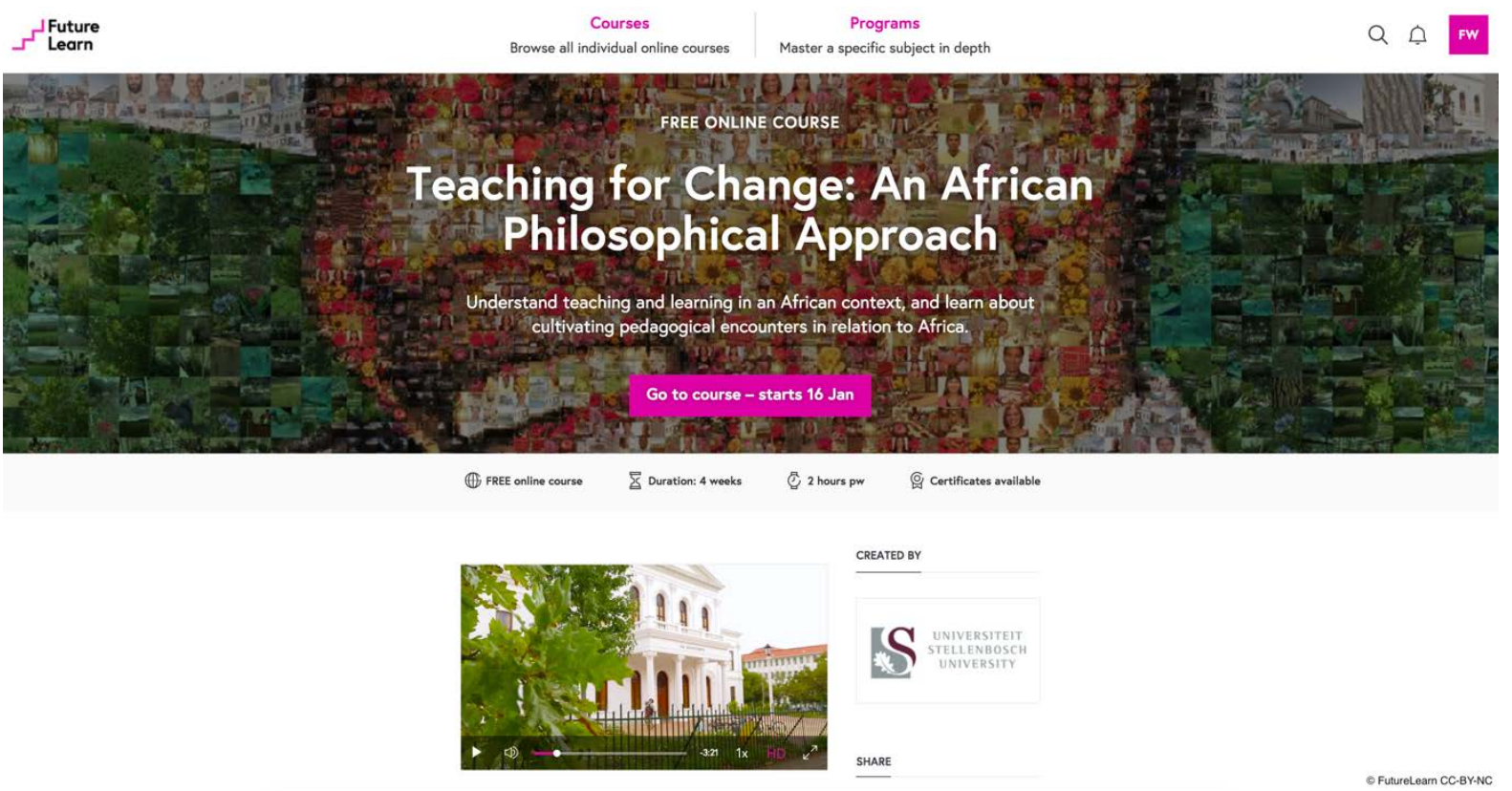

\section{Screen shot 1}

pedagogical initiatives to provide access to non-traditional university students to engage in higher education studies. Basically, MOOCs 'are online courses mediated by information and communication technology' (Klobas, Mackintosh and Murphy 2015, 10). As one of the leading universities in South Africa, Stellenbosch University, like the University of Cape Town and Witwatersrand University, has recently implemented its first MOOC entitled 'Teaching for Change: An African Philosophical Approach'. The rationale for this MOOC is aimed at engaging students in pedagogical activities that orientate them towards identifying major societal problems on the African continent and then to proceed with examining some of the implications of such problems for higher education in particular. This MOOC on African philosophy of education is not only geared towards making people think differently in and about education on the African continent, but also to show that philosophy of education can be thought about differently in relation to African higher education. At the link provided, you may get some idea of what the latter MOOC entails: https:/www.futurelearn.com/courses/africanphilosophy. Thus, this MOOC has been designed and developed within a conceptual framework of what it means to engage in pedagogic encounters if one were to be situated in an educational institution or to participate in an educational practice uniquely relevant to Africa. Put differently, for too long higher education on the African continent had been subjected to some of the prejudices of Africa's former colonial powers. One way of contributing towards a decolonisation agenda is to show how African higher education could be reconceptualised within a post-colonial paradigm that draws on ideas and concepts that could foreground African thinking and doing. From the outset, we want to accentuate that decolonised discourses such as 
the transformative pedagogic encounters we advance in and through this MOOC, involve embarking on critique, uncovering encounters that are more plausible in terms of listening and deliberation, and more poignantly, cultivating encounters that remain in potentiality, that is, these encounters are inconclusive which also emphasise that there will always be more to know and more to learn.

Moreover, generally, MOOC learners include mostly school learners, university students, and life-long learners of which many in this latter group already have some university qualification (Klobas et al. 2015, 17). Some of the reasons offered as to why students enrol for MOOCs range from pleasure and experience of MOOC participation, to those concerned with utilitarian motivations, that is, reasons mostly associated with instrumental returns gained from participation or, in some cases, completion (Klobas et al. 2015, 17). We infer from some of the comments from students that many of those who enrolled for the MOOC on 'Teaching for Change: An African Philosophical Approach' wanted to deepen their knowledge of African education and or even to think differently about such a form of education, whereas others students considered the MOOC an entry into a leading African university at which they could pursue a university course.

For this specific course, dystopias such as dictatorships, food insecurity, terrorism, student protestations against fee increases, and mediatory processes of truth and reconciliation have been identified as main societal problems besetting contemporary societies. In an analytical way, students in the MOOC, ‘Teaching for Change: An African Philosophical Approach', are expected to examine some of the implications of the afore-mentioned problems for higher education, more specifically teaching and learning in higher educational institutions. In the main, the philosophical approach of identifying a problem and looking for its educational implications, underscores the pedagogical activities on which students and university teachers (us) embark collectively. The latter approach to analytical educational inquiry is linked to what has been couched as 'African philosophy of education' (Waghid 2014). Such a philosophy of education is constituted by what is known as 'traditional ethno-philosophy' - for instance, using artefacts, poems, literature and cultural experiences of Africans to analyse education - on the one hand, and communitarian philosophy of education (that is, doing things in community without abandoning one's autonomy) on the other. Together, these two interrelated forms of philosophy of education have been articulated as an Ubuntu philosophy of education, that is, a philosophy of education geared towards the cultivation of humaneness, human interdependence and co-operation, and justice.

Interspersed with videos, summaries of texts, activities and podcasts (audio recordings of 
a university teacher's responses to student queries), the course is presented over a four-week period allowing for autonomous, deliberative student engagement in and about understandings of African philosophy of education and its implications for pedagogical change - a matter of embarking on decolonisation of higher education in and about Africa. Together with our collaborating partner, FutureLearn in the United Kingdom, students are exposed to online course material and activities that allow them to engage critically with one another and with the thoughts and responses of the lead educator (that is, the co-author of this article). Some other MOOC platforms and university choices for partnerships include Coursera (United States), edX (United States), Blackboard Coursesites (United States), and ALT (United Kingdom) (Haywood and Macleod 2015, 47). Among the most pertinent pedagogical decisions that have informed the design and development of the MOOC of our institution, have been the following:

- $\quad$ course rationale, goals and themes;

- $\quad$ course timing and pacing;

- $\quad$ course structure and content, including exercises, quizzes and self-assessment activities; and

- $\quad$ assessment of the course in relation to course outline and content. (See Screen shot 2 where we have included some design format of the course).

1.3 1 MORE STEP TO GO

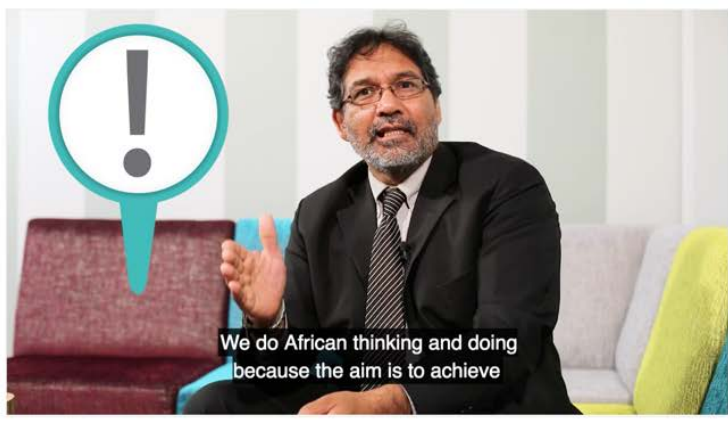

What does African philosophy of education mean?

Giving thought to African philosophy of education

1. What does African philosophy of education mean? Mindful action involves looking for reasons.

2. African philosophy of education is action as it points to doing or enacting
COMMENTS

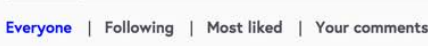

FW

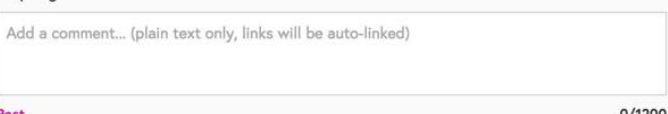

Post

Follow 14 OCT

Epistemological shifts

2. Social justice; inclusivity, valuing indigenous knowledge(s); democratizing learning spaces; responsiveness to context; foregrounding subjugated narratives and knowledges; changing; intitutional cultures; pluratility and knowledge systems/philosophies as sites of contestation and acknowledgement.

3. Critical, dialogical, embodied pedagogies.

OLike $1 \mp$ Reply

https://mww.tuturelearn.com/profiles/379102 adopted by African philosophy of education. And I do believe that only with EDUCATION we can face life's challenges.

$i$ agree with him.

O Like $\Phi_{\text {Reply }}$

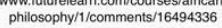

لhttps:/www.futureleam.com/profiles/782129 Fistly, you have been introduced to the afor tioned paradigm. What do you think an An African philosophical framework could involve thinking in a way that benefits the whole community. It would involve African ways of thinking about life, death, education, and the Secondly, if you have clarity of an African philosophy of education, what do you think the purpose of such a framework is or ought to be? $\quad$ Futurelearn CC-BY-NC

\section{Screen shot 2}


Therefore, besides having followed established instructional and web design techniques, we want the students who participate in our MOOC initiative to act autonomously yet deeply respectful of other learners with whose thoughts and ideas they could engage critically. This implies that our self- and open assessment activities invariably have to invoke students' potentialities as they endeavour to speak their minds - a view of learning commensurate with what it means to decolonise higher education in Africa. In other words, students are not just told what to do, but are also motivated to reach their own justifiable conclusions. It is in light of the aim of the course that students should come to speech that we shall now examine how three different and intertwined understandings of learning contribute towards the enhancement of what can be referred to as a 'pedagogy of decolonisation'.

Next, we examine why a case can be made for rhizomatic, critical and recognisable pedagogy as a corollary of human actions (of both students and lead university teacher) of a decolonised kind.

\section{TOWARDS RHIZOMATIC, CRITICAL AND RECOGNISABLE ACTIONS THROUGH MOOCS}

Our course design and development, especially the authoring, instructional design and video recordings, can be presented as a rhizomatic map that 'is open and connectable in all of its dimensions: it is detachable, reversible, susceptible to constant modification ... [with] multiple entryways and exits ...' (Deleuze and Guattari 1987, 12). Referring to the four themes, students were encouraged to (re)construct meanings of an African philosophy of education that could be detached from a linear understanding of knowing things. That is, students did not have to examine first what an African philosophy of education means before embarking on some pursuit of what the implications of this approach would be to higher education and concomitantly to an education for social justice. In much the same way as examining a rhizome, students could start off with a 'shattered' or 'broken' thought at any point in the course and then rupture their thoughts in such a way that these thoughts followed their own 'lines of flight'. Therefore, a thought is rhizomatic in the sense that '[i]t has neither beginning nor end, but always a middle (milieu) from which it grows and [from] which it overspills' (Deleuze and Guattari 1987, 21). When students embark on such an approach to learning, they pursue 'lines of segmentarity and stratification' or 'lines of flight' by which they come to enunciate 'assemblages' of understanding not in some arborescent or hierarchical way - such as moving from one point of understanding to another - but rather, in a way that signifies 'coming and going rather than starting and finishing' (Deleuze and Guattari 1987, 25). Put differently, 
learning rhizomatically as encouraged through this course, means that students could connect any particular thought to any other thought - establishing different lines of flight - in their attempts to 'make new connections' (Deleuze and Guattari 1987, 15). As pointed out in some of the comments in Screen shot 3, students pursued different 'lines of flight' to derive particular understandings of an African philosophy of education.

The origin of education can be traced back to man's history. This means that education existed for as long as human beings started living in their societies in Africa. This type of education was known as indigenous African education or traditional African education. This type of education existed in Africa way back before the coming of the missionaries. However, the missionaries came along with what is known as modern education or western education. Each form of education had its own strengths and weaknesses. It was only looking after the weaknesses of traditional indigenous education did the missionaries conclude that Africans were uneducated. Little did the missionaries consider the merits of indigenous African education.

Liked 10 † Reply https://www.futurelearn.com/courses/african-philosophy/1/ comments/15820687

The view that African were without education or uncivilised was a European perspective, much remote from truth. Africa had its own educational system, coherent culture and value systems that created communalism and shared values.

Like 5 philosophy/1/comments/15825105

Support the comments above, and yes the question of two bodies of knowledge that are constantly in conflict with each other.

\section{Screen shot 3}

Next, the question is: What makes such a way of learning critical? To practice criticism - a matter of learning to act critically - involves students being 'grown up enough to make up their own minds' (Foucault 1988, 152). In their identification of problems on the African continent, the students described here showed the capacity 'to grasp the reality of those problems and to react to them' (Foucault 1988, 152). As lead university educators, we encounter many students making up their minds about societal problems without always having to be told why the problems are so pernicious to education. The students whose quotes appear here show the inclination to resolve problems in a critical manner. This involves students 'pointing out on what kinds of assumptions, what kinds of familiar, unchallenged, unconsidered modes of 
thought the practices that we accept rest' (Foucault 1988, 154). In a different way, it seems students no longer thought of problems on the continent as they perhaps formerly thought of them. Their thinking had been transformed 'in a free atmosphere' whereby they expressed their views about the problems, constantly being agitated by ‘a permanent criticism’ (Foucault 1988, 155). The discussion among students as shown in Screen shot 4 corroborates their interest in learning to 'speak up’ as an instance of criticism.

Interesting - having worked briefly in the voluntary sector within schools in parts of Africa, I have witnessed the tendency for colleagues to follow certain rules and not 'speak up' or offer new ideas. I am now questioning whether this is partly due to militant history and dictatorship, which although not present in those countries now, is perhaps embedded somehow in the culture - including that of education.
Like $6 \quad+$ Reply
https://www.futurelearn.com/courses/african-philosophy/1/ comments/15820790

Not speaking up, contributing or questioning rules/guidelines isn't inherent to places that have suffered under a military dictatorship. I'm sure you can find examples of such behaviour in any school. I know I can!

Like 4

https://www.futurelearn.com/courses/african-philosophy/1/
comments/15820790

https://www.futurelearn.com/profiles/3262964

Follow 20 SEP

I have worked for several years in China, and when teaching adults in a new school I was often given a list of topics that should not be addressed during class. Sometimes the lists were vague (don't talk about things that go against "Chinese traditional values" or "disturb social harmony"), other times they were more detailed (no politics whatsoever, no movies, books, or bands/songs related to social injustice or riots or just the simple feeling of unhappiness). We were also told not to answer any question coming from students as well.

Like 4

https://www.futurelearn.com/courses/african-philosophy/1/
comments/15869885

EL https://www.futurelearn.com/profiles/3070819

Follow 21 SEP

Totally agree! I wasn't referring it to being only linked with military rule and have also seen it happen a lot elsewhere. But had never thought about the possible link before.

Like

https://www.futurelearn.com/courses/african-philosophy/
$1 /$ comments/15820790

\section{Screen shot 4}


My interest in this course is very broad, education in general, global education. I'm a history major, 63 years old, and living in the Upper Peninsula of Michigan (U.S.). We are approaching a global population of eight billion, and many anthropologists believe we are now in the "anthropocene". My own education; Catholic elementary school grades 1-8, public secondary education 9-12, and public university with a B.S. degree in history. Historically speaking, the goal of education has been to make the individual a part of the group, or state. I am in search of a new educational paradigm, one that brings people together, instead of an US vs THEM mentality. As far as we know this planet we live on is a singularity in the universe. And if we don't start teaching that there is only one race, the human race, living on it we are doomed for continual conflict over the limited resources that remain. The one thing we all share is being human, beyond that, sex, ethnicity, religion, and where we are born, are all tools that are used to divide us. Looking at the current political conflicts around the world the divide and conquer mentality is working very well, we need to do better, and fast!

$\begin{array}{ccc}\text { Like } 6 \quad \text { Teply } & \begin{array}{c}\text { https://www.futurelearn.com/courses/african-philosophy/1/ } \\ \text { comments/15801499 }\end{array}\end{array}$

I worked in Botswana for about 8 years in teacher education, in particular the field of special and inclusive education. The advantage of that field is that you are aware from day one that the cultural milieu is fundamental to people's understandings and practices and that one should tread very lightly indeed in coming to any judgement about these. I also became interested in teacher education in general in southern African contexts and have written a paper with a colleague from Zambia positing the idea that many concepts that we assume are 'Western' in origin with regard to teaching practices actually pre-existed in many traditional teaching practices in African education. So for example the idea of multiple intelligence is written about and theorised in a Western context but existed as practice in traditional education (songs / poems / drama / stories / kinetic learning for example). So by inviting their students to consider these ideas as classroom practice African teacher educators are not simply aping Western notions but reclaiming deep and culturally relevant norms.

I continue to be actively involved in projects regarding the education of learners with albinism in s'n Africa. https://www.futurelearn.com/courses/african-philosophy/1/

Like 6 Teply comments/15841512

\section{Screen shot 5}

What has been quite significant about the pedagogical exchanges that occurred among these students and ourselves, has been the willingness of all to speak their minds and to act within the present. That is, we were intent on listening to one another's views and criticisms, as is evident in our comments of engagement. We were not affronted by one another's comments even if such comments appeared belligerent and distressful at times. In a way, our encounters were guided by the art of recognition. Following the seminal thoughts of Giorgio Agamben (2011, 46), it is only through recognition of others that a person constitutes herself/himself as a person. For once, students publicly exhibited their thoughts in 'the absence of secrets [and] beyond all mystery and meaning' (Agamben 2011, 90). In other words, students were not afraid 
to denude their thoughts to the extent that they were willing to share with others what they were thinking and in this way wanted to be recognised as humans willing to disclose what they know. See Screen shot 5 for some comments and exchanges amongst students that confirm their insistence on being recognised as persons in pedagogical practice.

This brings us to a discussion of how the MOOC on 'Teaching for Change: An African Philosophical Approach’ engendered disruptive pedagogic encounters. Our reason for focusing on disruptive pedagogical encounters is corroborated by the argument that in any act of decolonisation in which thoughts and practices ought to be framed differently, one ought to rely on a pedagogical art of disruption in order to unsettle the taken-for-granted, established and often debilitating understandings of education.

\section{AFRICAN PHILOSOPHY OF EDUCATION AND THE CULTIVATION OF DISRUPTIVE PEDAGOGIC ENCOUNTERS: REFLECTING ON THE 'TEACHING FOR CHANGE' MOOC}

At least three salient benefits can be identified in the quest to cultivate disruptive pedagogical encounters in higher education through MOOCs. Firstly, students' experiences with the 'Teaching for Change' MOOC enhanced their deliberative interaction with learning course material in association with online peers. Through this MOOC, students learned together and from one another especially 'by real access to other students around the world' (Ranaghi, Saberi and Trumbore 2015, 97). In other words, the potential of students to rethink taken-for-granted assumptions in their lives through the power of the social web has been amplified (Ranaghi et al. 2015, 97), as corroborated by the student mentioned in Screen shot 6 .

sw

Thank you so very much Professor Yusef this has been a most enjoyable and stimulating course and one cannot but be dismayed at how worldwide all of the participants have been. Here in Scotland I have at an instant been connected to not only the course but the most beautiful collages every day on our screens, and I have learned so much both from yourself but also the posts from other fellow students. African Philosophy of Education is now in the minds of so many of us. Thank you.

\footnotetext{
Liked 1 Reply https://www.futurelearn.com/courses/african-philosophy/1/comments/165601/15 (c) FutureLearn CC-BY-NC
}

\section{Screen shot 6}

Secondly, the high level of student engagement in the absence of the traditional incentive of a university degree is inspiring. The opportunity students' comments offered others and us to learn from their intellectual work is immense, especially considering how students uniquely 
create their own pathways to learning. The latter aspect of learning is confirmed in the discussion in Screen shot 7.

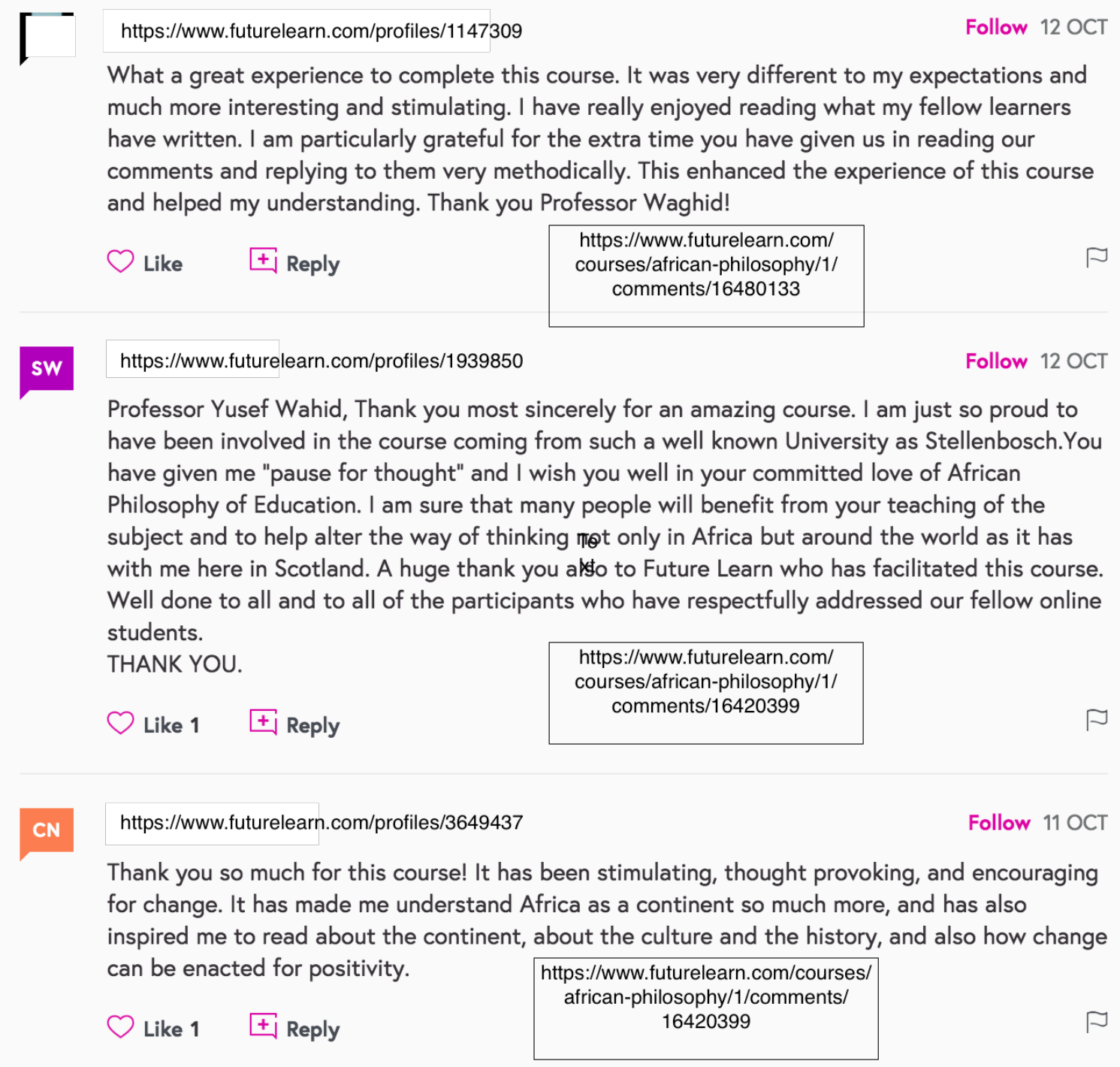

\section{Screen shot 7}

Finally, to have become a learner outside the physical classroom brought to the fore another aspect of learning, that is, a learning revolution that enabled these students to create connections and meanings that would invariably affect their own lives as corroborated by a student as shown in Screen shot 8.

For students to have created their own connections and meanings about the course content, which potentially affected their thoughts and practices, it can be argued that these MOOC students came to express what Jacques Rancière refers to as their 'equal intelligence' - that is, through the MOOC course material students were summoned to use their intelligence (Rancière 1991, 39). In this way, the students demonstrated the capacity to learn for themselves without always having to be dependent on the university educator. In other words, the university 
educator did not assume that students lacked the capacity to speak and offer comments. Rather, in a subjectified or disruptive way, students autonomously appeared within the pedagogical activities and began to reconfigure their learning experiences (Rancière 1999, 35). That is, students were able to come to their own speech as they interrogated the course material. Our role as university educators was to remind these students that they can see and think for themselves and that they (students) are not dependent on others for their learning, more specifically that they (students) can see and think without our teaching. As Rancière $(1991,12)$ puts it, these students learned without a 'master explicator' - that is, we (university educators) engaged in teaching without explanation 'by summoning ... [MOOC] students to use their

https://www.futurelearn.com/profiles/81364

Follow 25 SEP

I worked in the rural areas of what was Rhodesia in the 1960's. The African Philosophy of Education that I experienced was that grandmothers taught their grandchildren through raconteur of the ways of previous generations, providing education in the social graces, how to greet their elders, how to behave in society, how to care for the menfolk. Uncles taught their nephew's how to tend the cattle and goats, how to hunt wild animals. Times change, technology advances. When I attended a conference in 2000 to discuss the shortages of teachers in rural areas of the new Zimbabwe and devise solutions, I suggested that the grandmothers be brought back into action. I was told that this was not a practical solution as they were technology illiterate and could not help.

Like 2

https://www.futurelearn.com/courses/africanphilosophy/1/comments/15946238

\section{Screen shot 8}

intelligence' (Biesta 2011, 34). Furthermore, students learned without explanation by (de)constructing meanings in the course, thus having created their own paths to learning and having amplified the possibility for societal change. Students and university educators were intellectually equal in the very act of disrupting the MOOC pedagogical activities.

\section{CONCLUDING REMARKS}

This MOOC on 'Teaching for Change' can be associated with the cultivation of democratic education that remains in potentiality. Students and ourselves recognised that, in the pedagogical activities of the MOOC, there is always the potentiality on our part to see things anew, and to think differently about our pedagogical experiences in relation to societal matters of concern and vis-à-vis our deliberative pedagogic encounters. In a way, the MOOC offered us (students and university educators) an opportunity to engage in what Jacques Derrida refers to as a 'democracy to come' - that is, a radical possibility of deciding and making come about 
(Derrida 2004). The MOOC has the structure of a promise and not of orienting students towards pedagogical certainty for bringing about change tomorrow. When the students engaged with societal problems in an analytical fashion they came to the realisation that societal change has the potentiality 'to come about', thus linking their pedagogical encounters with (im)possible human experience (Friedrich, Jaastad and Pokewitz 2011, 70). It is not that change would ensue instantly. Rather, through disruptive pedagogic encounters, societal change becomes imminent - that is, there is always the possibility that change would be realised.

At the moment, we remain optimistic about the pedagogical advantages of MOOCs in the sense that students are included in pedagogical activities and are recognised for their coming to speech. In this way, learning though MOOCs is potentially liberating in the sense that students can act autonomously with pedagogical content and even contribute towards (re)shaping such content. MOOCs cannot be considered acritical pedagogical courses primarily because the potential is always there for students to act with an openness to others' points of view without necessarily withholding and/or abandoning their own critical judgements. Such a form of learning then is associated not only with criticism in a Foucauldian sense but also with the cultivation of democratic experiences that are yet to come for the reason that what is yet to come is contrived and deliberated on collectively or democratically. Such democratic encounters would invariably motivate students and curriculum developers towards considering their work as always in potentiality as there is always more to be known because one cannot completely know at a given point in time. Our MOOC experiences have been guided by what is still to come, as ongoing critical student feedback on new pedagogical courses invariably influences the authenticity of curriculum (re)design and development. At the time of concluding this article, the MOOC ('Teaching for Change') had just run its second course on the FutureLearn platform. After our evaluation of the second group of students' comments we have come to understand that their pedagogic authorities have been deepened by their willingness to come into presence of one another - that is, their own acts of decolonisation have been significantly guided by the willingness and openness to rupture the fractured notions of African higher education that have dominated the continent for so long. In turn, these students have given us more optimism that changing pedagogic encounters vis-à-vis decolonised teaching and learning discourses can happen only on account of disrupting the present with the aim to engender what is perhaps yet unimaginable!

\section{REFERENCES}

Agamben, G. 2011. Nudities. D. Kishik and S. Padatella (Trans.). Stanford, CA: Stanford University Press. 
Biesta, G. 2011. Learner, student, speaker: Why it matters how we call those we teach. In Rancierè, public education and the taming of democracy, ed. M. Simons and J. Masschelein, 31-42. London: Wiley-Blackwell.

Deleuze, G. and F. Guattari. 1987. A thousand plateaus: Capitalism and schizophrenia. B. Massumi (Trans.). Minneapolis, MN: University of Minnesota Press.

Derrida, J. 2004. Eyes of the university: Right to Philosophy 2. J. Plug and others (Trans.). Stanford: Stanford University Press.

Foucault, M. 1988. Politics, philosophy, culture: Interviews and other writings 1977-1984. L. D. Kritzman (Ed.). London: Routledge.

Friedrich, D., B. Jaastad and T. S. Popkewitz. 2011. Democratic education: An (im)possibility that yet remains to come. In Rancierè, public education and the taming of democracy, ed. M. Simons and J. Masschelein, 60-75. London: Wiley-Blackwell.

Haywood, J. and H. Macleod. 2015. To MOOC or not to MOOC? University decision-making and agile governance for educational innovation. In Massive open online courses: The MOOC revolution, ed. P. Kim, 46-60. New York, NY: Routledge.

Kim, P. (Ed.). 2015. Massive open online courses: The MOOC revolution. New York, NY: Routledge.

Klobas, J. E., B. Mackintosh and J. Murphy. 2015. The anatomy of MOOCs. In Massive open online courses: The MOOC revolution, ed. P. Kim, 1-22. New York, NY: Routledge.

Rancière, J. 1991. The ignorant schoolmaster: Five lessons in intellectual emancipation. Stanford, CA: Stanford University Press.

Rancière, J. 1999. Disagreement, politics and philosophy. Minneapolis: University of Minnesota Press.

Ronaghi, F., A. Saberi and A. Trumbore. 2015. NovoEd, a social learning environment. In Massive open online courses: The MOOC revolution, ed. P. Kim, 96-105. New York, NY: Routledge.

Waghid, Y. 2014. African philosophy of education reconsidered: On being human. London: Routledge. 